\title{
Psychological Health Restoration as a Way of Socio-Psychological Rehabilitation of a Person
}

\author{
Tetiana Tytarenko \\ Institute for Social and Political Psychology of NAES of Ukraine, Kyiv, Ukraine
}

Introduction. Socio-psychological influences are not strictly aimed only at the restoration of the lost mental functions or at the returning of social status after the military intervention. The ultimate goal of socio-psychological rehabilitation is an achievement of a qualitatively new level of psychological health which provides an increase in subjective satisfaction with life. The war trauma creates potent barriers to veterans' lives and these barriers obstruct recovery and personal growth (Zinzow, 2012). There are the alarming data about the state of veterans, which requires a long-term rehabilitation (Morina, 2007; Romero, et al., 2015; Rudd, et al., 2011).

The purpose of the investigation is to develop the technologies for psychological health restoring after the war-related trauma.

Methodology. In order to find the indicators of personality's psychological health the indirect contextual interview technique with the procedure of an intellectual filtration was chosen. For receiving definitions of the healthy personality there were analyzed the theories the 32 classics of psychological science. The content analysis with the procedure of an intellectual filtration and frequency of indicators was used. Indicators with a high frequency were determined. Recovery technologies which we developed are based on these indicators and criteria of psychological health.

Results. It was shown that the core of psychological health includes personal integrity, the need for self-realization, and the capacity for self-regulation. Three levels of peripheral indicators were identified. On the individual psychological level - creativity, harmony, adaptability. On the value-semantic level - the creation of meaning, understanding the experience and the ability to enjoy life. On the socio-psychological level - the tendency for cooperation, capacity for empathy and trust to the outside world.

The following criteria for psychological health were allocated: 1) the ability to update personal integrity and self-esteem; 2) the possibility of strengthening the need-motivation and valuesemantic personal resources; 3 ) the possibility of self-efficiency and self-realization increasing; 4) the ability to restore the capacity to build the constructive relations with the environment.

Socio-psychological technologies of personality's rehabilitation are defined as the complex targeted impacts which provide the preservation and restoration of the psychological health. The process of the socio-psychological restoration of the individual is divided into the following stages: preparatory, basic, and supporting which also acts as the prophylactic one. On each stage the appropriate rehabilitation technologies and certain individual and group techniques were tested. We use social, common practices as life-designing techniques, ways of a lifeimplementation which are approved, repeated, fixed and arise in a course of continuous dialogue of a person with a community. Every practice is a way of self-designing in specific life circumstances.

At the preparatory stage of rehabilitation, the following technologies were approved as effective ones: the technology of self-change motivation enhancing, the technology of effective motivators constructing, and the technology of blind fields of attention activating.

At the basic stage the following technologies were approved as effective ones: the technology of the future designing through life choices, the technology of updated projects by means of life tasks setting approbation, and the technology of the set tasks realization. 
At the supporting stage the following technologies were approved as effective ones: the technology of reinterpretation and integration of traumatic memories into the personality's auto-narrative, the technology of the new attitude to stress as the resource developing one, and the technology of mediated influence on the personality through the more ecological life organization.

The strength of the study is the development of original technologies for restoring the psychological health after a war-related trauma.

Limitations of the study. There is no data on the special categories of people who are in need of psychological rehabilitation (combatants; their families; forced migrants).

Practical value. The results of this work should provide a useful foundation for psychological service delivery for persons who suffer from military trauma.

Conclusions. The restoring of psychological health after a war-related trauma involves the deployment of each technology in some pathways. First, the technologies are directed on the restoration of personality's balance and self-regulation. Second, the work is targeted on the restoring of lost self-efficacy and personal ability to self-realization in various activities.

Third, we focus on the communicative competence increasing, the relationships' establishing, the constructive conflict resolution. Fourth, we try to concentrate attention on the reevaluation of values, the search for new life benchmarks and new senses.

Keywords: social rehabilitation, personality, quality of life, trauma, mental health.

\section{References.}

1. Morina, N. (2007). The role of experiential avoidance in psychological functioning after war-related stress in Kosovar civilians. Journal of Nervous and Mental Disease, 195(8), 697700 .

2. Romero, D.H., Rigs, S.A., \& Rugerro, C. (2015). Coping, family social support, and psychological symptoms among student veterans. Journal of Counseling Psychology, 62(2), 242-52.

3. Rudd, M.D., Goulding, J., \& Bryan, C.J. (2011). Student veterans: a national survey exploring psychological symptoms and suicide risk. Professional Psychology: Research and Practice, 42(5), 354-360.

Zinzow, H.M., Britt, Th.W., McFadden, A.C., Burnette, C.M., \& Gillispie, S. (2012).

Connecting active duty and returning veterans to mental health treatment: Interventions and treatment adaptations that may reduce barriers to care. Clinical Psychology Review, 32, 741753 